\title{
DESIGNING CLASSROOM ACTIVITY: TO UNDERSTAND THE KEY PSYCHOLOGICAL PERSPECTIVES IN AN INTRODUCTORY COURSE
}

\author{
Rubayat Kabir \\ East West University, Bangaladesh
}

\begin{abstract}
Introductory classes are essential for understanding any course. In a traditional class format, the instructor delivers lecture to students who passively grasps the information presented to them. However, recent researches emphasize on the importance of active student engagement in classroom for better retention. The paper presents a demonstration of class activity designed to engage students in introductory psychology course for undergraduate students. It tries to foster critical thinking and application of various viewpoints through class participation. The study took place in two sections of Introduction to Psychology course with 84 participants in Dhaka, Bangladesh. In one section, a class of one hour and thirty minutes was allocated for the activity, i.e. five groups were created to represent five Psychological perspectives, case reading and presentation was done in groups as well as question and answer round took place among each group. In another section, the case was presented to students for reading and analyzing it during their free time after class. The responses were marked from their examination scripts. The result indicates a significant difference in responses from those who took part in the class activity than those who did not. The students had better recall of elements from the case and could relate more to real life situations.
\end{abstract}

Keywords: Psychological perspectives, Classroom Activity, Introduction to Psychology course

\section{Introduction}

The course introductory psychology is typically offered to students either at their high school level or at an undergraduate program. It is rather demanding and commonly taught course in colleges (Gurung et al, 2016). Likewise, in the context of Bangladesh, the course is generally provided at the undergraduate level and further on. The subject gets offered both as a core course or an optional one. Meaning, if you are doing your major in Psychology, it automatically gets included or it may also have an association with other discipline such as English, Bachelor of Business Administration, Journalism, Law or any other discipline parse.

Earlier, it has been noticed that teachers widely using traditional lecture method to teach undergraduate students (Lom, 2012). Perhaps because the teachers experienced the same format of learning while they were students (Wurdinger and Carlson, 2010). When instructors teach their students, they usually tell them what they know instead of how they know it (Churchill, 2003). In support of this approach, the traditional form of lecture seems to be more convenient, even though, its exclusive use has been negatively viewed (Lom, 2012). In addition, several studies do show that only traditional lectures are not as effective as compared to active learning strategies (Tanner, 2009). However, there have been discrepancies in different disciplines. Activity-based classes have long been popularized within the humanities discipline (Berens, 2014).

Activity based learning implicates students being an active participant rather than just passive listener (Khan et $a l$, 2012). This is a kind of instructional method engages participants in class room through the use of in-class written exercises, games, problem sets, audience-response systems, debates, class discussions and many more 
(Miller and Metz 2014). This format allows learners to develop their own cognitive abilities (Churchill, 2003). The learning experiences can be categorized in several ways. Dewey popularized the concept of Experiential Education which focuses on problem solving and critical thinking rather than memorization and rote learning (Kolb, 1984).

"Experiential learning is a philosophy and methodology in which educators purposefully engage with students in direct experience and focused reflection in order to increase knowledge, develop skills, and clarify values" (Association for Experiential Education). The reason behind the term 'experiential' was primarily because the theory combines philosophical pragmatism, social psychology and cognitive-developmental perspective on learning. However, the purpose of activity based classes is not to replace lectures but to act as a support (Gilgeous and D’Cruz, 1996). Some of the ideas to foster good education among the undergraduates are: encourage student-faculty contact, boost cooperation among students, emphasize on active learning, provide prompt feedback, time on tasks, communicate high expectations and respect diverse talents and ways of learning (Chickering and Gamson, 1999).

\section{Literature Review}

A growing body of literature looks into application of Activity- based learning. The review is segmented into few categories based on the intention and the findings of the studies. The first part looks to a comparison between different approaches to learning.

In a study done by Khan et al (2012) on Physics class of $9^{\text {th }}$ standard secondary school student's one group was taught with the help of activities whereas another group was taught through traditional method of teaching for the period of six weeks. The t-test analysis of the achievement tests showed that the activity- based teaching was more effective for the development of higher order skills.

In addition, Borchardt and Bozer (2017) conducted a study on a micro-flipped classroom which combined the traditional lecture-based course and the flipped classroom for a blended mixture of the two pedagogical approaches. The study allowed the instructor time to lecture in class, while promoting more interactive discussions between the students. Exam specific analyses revealed that exams resulted in significant higher grades in the micro-flipped class group and the benefits of the micro-flipped classroom could be realized within the course of one semester.

A study conducted by Walker et al (2008) on a lecture section of introductory biology of 500 students. A traditional lecture format was followed in the "traditional" section and lecture time in the "active" section was drastically reduced in favor of a variety of in-class student-centered activities. Students in both sections took unannounced quizzes and multiple-choice exams. Results demonstrate that students perform as well, if not better, in an active versus traditional environment.

Melton, Bland and Foss (2009) compared 251 student of health course in respect to achievement and satisfaction with blended learning course compared to a traditional face-to face class format. Satisfaction scores indicated difference in the two classes. Achievement by students of blended and traditional sections brought mixed findings, yet blended students' overall grades were considerably higher.

Moreover, Matthews (1997) included case studies and student presentations to the class along with lectures and demonstrations in biochemistry course in first year PharmD curriculum. The course structure used computerassisted lecture presentations and lecture handouts. This approach increased the motivation of the students to learn the material by helping them to see the application of biochemistry to the practice of pharmacy. 
Lumpkin and Achen (2015) investigated undergraduate sport finance and economics class, it was found that $72 \%$ of juniors and seniors reported out-of-class lectures positively impacted their learning. End of course response was significantly positive about class engagement, interaction, and enjoyment.

This segment of the literature specifies the reason as to why activity based learning is shadowed.

In one of the works performed by Miller and Metz (2014) in physiology class, the faculty member's reported a full-fledged focus on lectures rather than using simulation based activities. Even though students indicated that they learned best via the activities. The major stated barriers to use active learning were a lack of necessary class time, a high comfort level with traditional lectures, and insufficient time to develop materials. Despite these barriers, a majority of faculty members were interested in learning more about the alternative teaching strategy. Both faculty members and students indicated that active learning should occupy portions (29\% vs. $40 \%$ ) of faceto-face class time.

In Achen and Lumpkin's (2015) study in which students were given pre- and post-course surveys to assess perceptions on lecture time, impact of learning strategies, and enjoyment of learning strategies. Results indicated students spending the majority of class time actively engaged in their learning instead of passively listening to lectures. Even though students overwhelmingly enjoyed engaging learning activities and found them helpful, they still believed teachers should lecture more than $60 \%$ of the time, although the teacher in this course only lectured $30 \%$ of the time.

This segment of the literature indicates the techniques used to foster activity based learning.

In an article, Lom (2012) highlights several collaborative teaching techniques such as reader's theatre, thinkpair-share, roundtable, jigsaw, in-class quizzes, and minute papers that can be readily deployed within traditional lecture frameworks to promote active learning. Each technique is broadly applicable well beyond neuroscience courses and easily modifiable to serve an instructor's specific pedagogical goals. The benefits of each technique are described along with specific examples of how each technique might be used within a traditional lecture to create more active learning experiences.

Miller, McNear and Metz (2013) engaged in interactive lectures followed by "breaks" that consisted of 1-minute papers, problem sets, brainstorming sessions, or open discussion. The use of engaging lectures led to a statistically significant higher average on unit exams compared with traditional didactic lectures. Furthermore, students demonstrated an improved long-term retention of information via higher scores on the comprehensive final exam. Many qualitative improvements were also indicated via student surveys and evaluations, including an increased perceived effectiveness of lectures, decrease in distractions during lecture, and increased confidence with the material.

\section{Methodology}

The study was designed to take place in two sections of Introduction to Psychology course with a total of 84 participants. The students of the course belonged to different departments of the University, thus the course being an elective one for them. In general these students have diminutive knowledge in the field of Psychology, which makes it difficult to further understand the basic perspectives of the field in a more holistic approach. The purpose was to observe the difference; if exists, between the traditional method of teaching as compared to activity based method of teaching among students in the respective classrooms specifically in understanding the Psychological perspectives of the field. 


\section{Activity Based Learning: The Process}

Thus, in one of the section, a class of one hour and thirty minutes was devoted for activity based method of learning. This led to a creation of five groups to represent five Psychological perspectives. In this case, the perspectives were Biological, Psychodynamic, Behavioural, Cognitive and Humanistic. However, previous to the activity class, a case study was distributed to every student for reading it after the class time and an announcement was made about the activity to take place in the next class based on the case that was distributed. The students who were present during the announcement were asked to inform their classmates who were absent in class.

On the day of the activity, the facilitator gain briefed the participants about the case study 'Growing Up in a Strange World' which is about the life of an autistic child, in case they failed to read and come to class (Plotnik and Kouyoumdjian, 2014). The students were then asked to create 5 groups consisting of 7-8 members in each group. Subsequently, each group had to decide on a group representative. Individual group representative were then asked to pick up chits from the five given options on a random basis. The topics were announced to the class by each group representative (Biological, Psychodynamic, Behavioural, Cognitive and Humanistic). Successively, each group then received an explanation/viewpoint of the case study based on the perspective they picked up. For example, the group that represented the biological perspective received the case analysis from the biological point of view.

The participants were then instructed regarding the whole activity process. At the commencement of the activity, they were asked to read the analysis of each case perspective. After every participant finished reading, they were asked to discuss the analysis with their group mates and note down important points from it. In between the discussion, the participants choose 2-4 members in their group who would brief other groups about the main theme from their perspective. Later, each group were given 5 minutes to discuss among themselves regarding the other groups perspective as compared to theirs and note down questions which would be asked after every group has finished presenting their case analysis. Repeatedly each group had to follow the same process.

Once completed, each group was given a chance to questions any other two groups regarding their presented perspective. Subsequent to the question round, each group received a chance to answer the questions raised for their group. The instructor controlled the timing as to when to stop and move to the next group. The session was then concluded by debriefing about the activity.

\section{Traditional Based Learning: The Process}

To the other section, the case including case discussions from the five perspectives was distributed to the students for reading and analyzing it during their free time after class. In the subsequent class, the topics/perspectives were further explained by providing example from each case.

\section{Results \& Discussion}

The responses were marked from their examination scripts. In both the sections, the number of students enrolled for the course was 42 for each. However, during the class wherein the case was discussed, 40 students were present from section one and in the second section 38 students were present. But, exam was given by 41 students in the first section and 40 students in the second section. In the exam similar question regarding the perspectives was asked to both the classes. 
Table 1 Students present in class activity and answered question in exam

\begin{tabular}{lll}
\hline & $\begin{array}{l}\text { Lecture Based } \\
\text { Learning Session }\end{array}$ & $\begin{array}{l}\text { Activity Based Learning } \\
\text { Session }\end{array}$ \\
\hline Present In Class & $90.48 \%(38)$ & $95.24(40)$ \\
\hline Answered In Exam & $95.00 \%(40)$ & $97.56(41)$ \\
\hline
\end{tabular}

Table 1 shows the percentage of students present during the class activity and the students who could answer the related question in exam. Not all the participants who answered in exam were same as who attended the class. Among them there were few participants who did not attend the class activity, yet they could answer the question in exam.

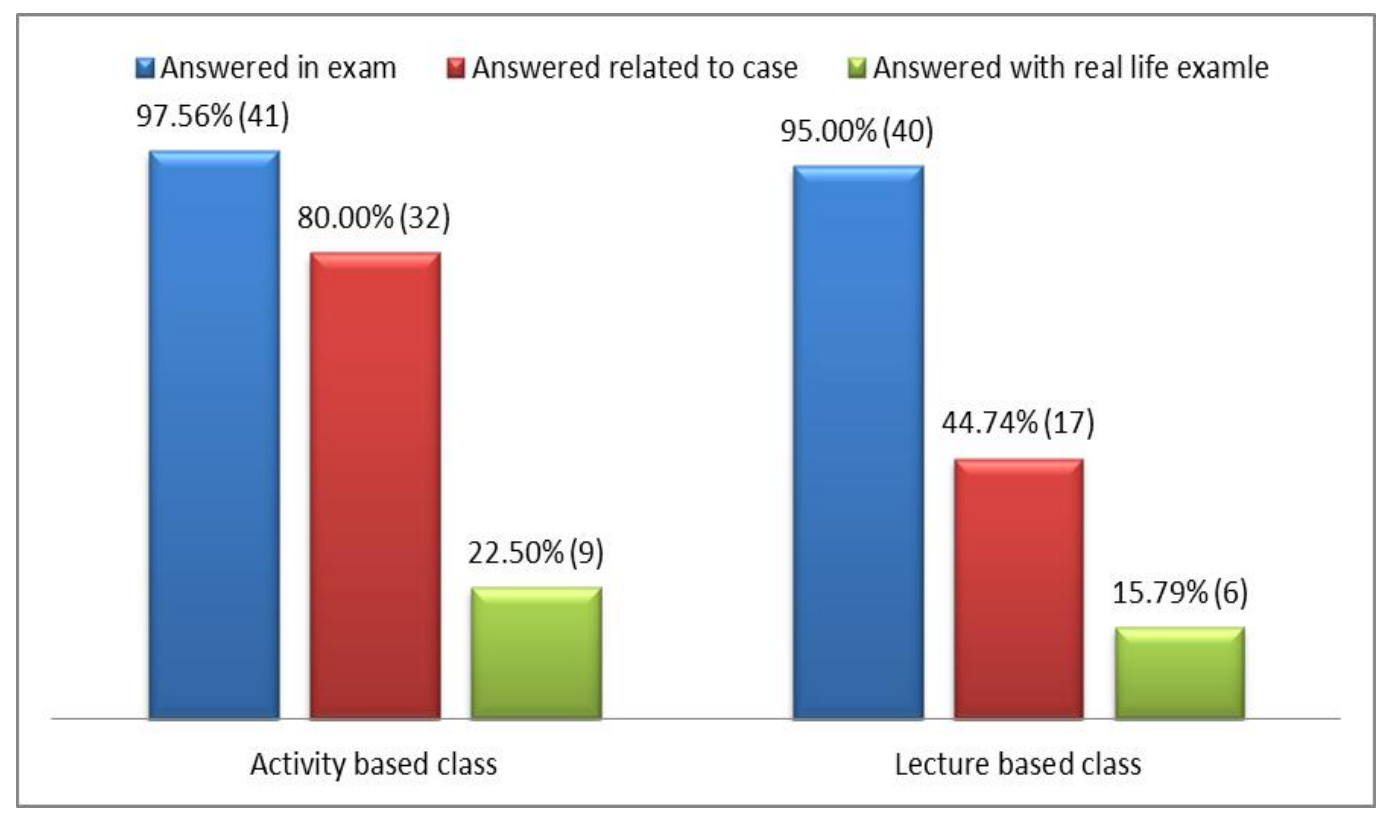

Figure 1: Comparison of Students Performance in Activity Based Learning Session and Lecture Based Session

Figure 1 shows comparison related to different components between the activity based learning class and traditional lecture based learning class. The three factors shown in this diagram includes students who attempted to answer the question during exam, who could include case analysis in their answer and the last factor includes answer that could relate to real life example. Noticeably, the results show significant difference in the factor relating to the answer with reference to the case discussed in class. In the activity based class, it can be seen that about 76 percent of the students could relate to the case discussed in class. Whereas, only 40 percent of the students could relate to the case in the traditional lecture based class. The noteworthy difference in this factor could possibly be because of what we experience can be retained better in our memory than what we just listen.

In addition, students of activity based class expressed their likeliness and satisfaction towards the activities designed for them during the whole semester. They recommended designing more of such activities because it made learning more engaging and enjoyable. Several studies have found that there is a higher rate of satisfaction in the blended learning course compared to traditional learning formats (Rovai and Jordan, 2004; Pereira et al., 2007).

\section{Conclusion}

Psychology is a subject that could be related to everyday real life experiences in and around us. Therefore, to teach the course at an undergraduate level, a teacher could try out different forms of learning. The success rate of indulging into activity based learning requires acceptability from both the teacher as well as from students. 
To bring about changes in the overall attitude, the university authorities along with the faculty members should work together on changing the overused traditional teaching system.

The activity based classes involves students more into critical thinking by using their cognition and experience. It makes them think outside the box. Also, students learn from peer experience, their doubts and queries; in case if there is any, can be answered by other members of the group. If students know and understand this way of learning, than learning is stronger and enjoyable. Their thoughts are not constricted to class room only.

Even though experiential form of learning is not new, yet its use is limited. Hence, if forthcoming research studies can document subject wise effectiveness of Activity based learning and teachers can be trained to apply it proficiently, the methodologies can bring about success in the near future.

\section{Reference}

Achen, R. M., Lumpkin, A. 2015. Evaluating Classroom Time through Systematic Analysis and Student Feedback. International Journal for the Scholarship of Teaching and Learning, 9(2), 1-18.

Association for Experiential Education, Retrieved from http://www.aee.org/

Berens, K. I. 2014, January 23. Double flip: 3 insights flipping the humanities seminar. Hybrid Pedagogy.

Borchardt, J., \& Bozer, A. H. 2017. Psychology course redesign: an interactive approach to learning in a microflipped classroom. Smart Learning Environments, 4(1), 1-9. doi:10.1186/s40561-017-0049-3

Kolb, D. A. 1984. Experiential learning: Experience as the source of learning and development. New Jersey: Prentice-Hall.

Chickering, A. W., \& Gamson, Z. F. 1999. Development and adaptations of the seven principles for good practice in undergraduate education. New Directions for Higher Education, (80), 75-81.

Churchill, D. 2003.Effective design principles for activity-based learning: the crucial role of 'learning objects' in Science and engineering education.

Dale, E. 1969. Audio-visual methods in teaching. (3rd ed.). New York: Holt, Rinehart and Winston.

Gilgeous, V., \& D’Cruz, M. 1996. A study of business and management games. Management Development Review, 9(1), 32-39. doi:10.1108/09622519610181757

Gurung, R. A. R., Hackathorn, J., Enns, C., Frantz, S., Cacioppo, J. T., Loop, T., \& Freeman, J. E. 2016. Strengthening introductory psychology: A new model for teaching the introductory course. American Psychologist, 71(2), 112-124. http://dx.doi.org/10.1037/a0040012

Khan, M., Muhammad, D.N., Ahmed, M., Saeed, F., Khan, S. A. 2012. Impact of activity-based teaching on students' academic achievements in physics at secondary level. Academic Journal International, 3(1), 146-156.

Lom, B. 2012. Classroom Activities: Simple Strategies to Incorporate Student-Centered Activities within Undergraduate Science Lectures. The Journal of Undergraduate Neuroscience Education, 11(3), 64-71.

Lumpkin, A., \& Achen, R. M. 2015. Flipping a Class: Active Learning and More of It. Sport Management Education Journal,9(2), 79-90. doi:10.1123/smej.2014-0042

Matthews, J. C. 1997 Intermeshing Passive and Active Learning Strategies in Teaching Biochemistry. American journal of pharmaceutical education, 61, 388-394.

Melton, B. F., Bland, H., \& Chopak-Foss, J. 2009. Achievement and Satisfaction in Blended Learning versus Traditional General Health Course Designs. International Journal for the Scholarship of Teaching and Learning, 3(1), 1-13. doi:10.20429/ijsotl.2009.030126

Miller, C. J., \& Metz, M. J. 2014. A comparison of professional-level faculty and student perceptions of active learning: its current use, effectiveness, and barriers. Advances in Physiology Education, 38(3), 246-252. doi:10.1152/advan.00014.2014

Miller, C. J., Mcnear, J., \& Metz, M. J. 2013. A comparison of traditional and engaging lecture methods in a large, professional-level course. Advances in Physiology Education, 37(4), 347-355. doi:10.1152/advan.00050.2013 
Ng, E. M. 2010. A Comparative Study of Blended Learning Activities between Two Classes. Proceedings of the 2010 InSITE Conference, 307-315. doi:10.28945/1254

Pereira, J. A., Pleguezuelos, E., Meri, A., Molina-Ross, A., Molina-Tomas, C., \& Masdeu, C. 2007. Medical Education, 41, 189-195.

Plotnik, R., \& Kouyoumdjian, H. 2014. Introduction to Psychology (10th ed., pp. 3-10). Wadsworth: CENGAGE Learning.

P. \& Jordan, H. M. 2004. Blended learning and sense of community: A comparative analysis with traditional and fully on-line graduate courses. The International Review of Research in Open and Distance Learning, 5(2).

Tanner, K. D. 2009. Talking to Learn: Why Biology Students Should Be Talking in Classrooms and How to Make It Happen. Cell Biology Education, 8(2), 89-94. doi:10.1187/cbe.09-03-0021

Walker, J. D., Cotner, S. H., Baepler, P. M., \& Decker, M. D. 2008. A Delicate Balance: Integrating Active Learning into a Large Lecture Course. Cell Biology Education, 7(4), 361-367. doi:10.1187/cbe.08-02-0004

Wurdinger, S. D., \& Carlson, J. A. 2010. Teaching for experiential learning: Five approaches that work. Lanham, MD: Rowman \& Littlefield Education. 